\title{
Search Design Policy, Digital Disruption and Competition Law ${ }^{\star}$
}

\author{
Valeria Falce ${ }^{* *}$ \\ Massimiliano Granieri***
}

\begin{abstract}
It is debatable whether traditional competition law tools and remedies are able to deal with the digital disruption and whether it is desirable to adjust or even replace categories that have proven to be mainly suited to tackle anticompetitive conducts associated with stable innovations in markets where static competition prevails. From a bottom-up perspective, such Grand Question could well be addressed looking at the European Google Shopping case, just adopted at EU level, that will be analysed below with the aim of assessing whether and to which extent the positive antitrust toolbox is flexible enough to effectively cope with the data-driven era.
\end{abstract}

KEYWORDS: Innovation, digital disruption, Google Shopping, abuse of dominant position, discrimination

\section{Introduction}

We live in the fourth industrial revolution characterised by the digitalization of entire sectors and activities. ${ }^{1}$

\footnotetext{
* Date of reception: 14 July 2017. Date of acceptance: 03 August 2017

${ }^{* *}$ Valeria Falce, PhD, LLM, is Full Professor of Competition Law and Intellectual Property, Università Europea di Roma, Dipartimento di Scienze Umane, Ambito di Economia, 00163 Rome, Italy, and Board member of ASCOLA - Academic Society for Competition Law. valeria.falce@unier.it

${ }^{* * *}$ Massimiliano Granieri, PhD, LLM, is Professor of Comparative Law, Università degli Studi di Brescia, Dipartimento Ingegneria Meccanica e Industriale, 25123 Brescia, Italy. massimiliano. granieri@unibs.it.

Whereas the Article is the result of a joint research work, Valeria authored paragraphs 2, 3, 4, 5, 6, 7, 9 and Massimiliano Granieri authored paragraphs 1, 8.

${ }^{1}$ OECD, "Hearing on disruptive innovation", DAF/COMP(2015)3; Alexandre de Streel and Pierre Larouche, "Disruptive Innovation and Competition Policy Enforcement", TILEC Discussion Paper, November 2015.
} 
What we experience as deeply new is the emergence of a data-driven economy where on the one hand data and services are traded and used across sectors and borders and, on the other hand, the data-driven innovations generate an unsolicited snowball effect for the mere fact of existing in the digital ecosystem. ${ }^{2}$

As a matter of fact, thanks to the digital technologies, innovations rely on, and benefit from, some of their inherent structural features, such as interconnection and network effects, disintermediation and scalability, providing rapid access to a potentially global customer base.

If the data-driven innovation ${ }^{3}$ is disruptive, the process of creative destruction is much faster, it affects the network at different layers and with different intensity, but always in an accelerated and dynamic way.

The implications for competition law and policy are enormous: disruptive innovations create new markets and affect all the others, revolutionise products design policy and market players business models at large. ${ }^{4}$

It is therefore debatable whether traditional competition law tools and remedies are able to deal with digital disruption and whether it is desirable to adjust or even replace categories that have proven to be mainly suited to tackle anticompetitive conducts associated with stable innovations in markets where static competition prevails. From a bottom-up perspective, such Grand Question could well be addressed looking at the European Google shopping case, which will be analysed below with the aim to assess whether and to what extent the traditional antitrust toolbox is flexible enough to effectively deal with the data era.

\footnotetext{
${ }^{2}$ Of course, the concept of disruptive innovation is not new in itself: Joseph Bower and Clayton Christensen, "Disruptive Technologies: Catching the Wave", Harvard Business Review 73 (1995): 43. ${ }^{3}$ OECD, "Report on data-driven innovation" (2015), available at http://www.oecd.org/sti/datadriven-innovation-9789264229358-en.htm.

${ }^{4}$ The economic implications of such revolution are disruptive as well and are described by Jeremy Rifkin, "The zero marginal cost society", New York (2014), which predicts the eclipse of capitalism as a consequence of a new paradigm of collaboration, enabled by digital technologies.
} 


\section{A global focus on search design policy}

The debate on search design policy and its intersection with competition law is fueling around the world. ${ }^{5}$ This is not a surprise considering that different jurisdictions, US first, focused on the idea itself of "search bias". 6

As known, in 2011 and later in 2012 the US Federal Trade Commission conducted an extensive investigation into allegations that Google had manipulated its search algorithms to harm vertical websites and unfairly promoted its own competing vertical properties. ${ }^{7}$ The conclusion reached in 2012 was that the features of the search engine, Universal Search, as well as the additional changes made to Google's search algorithms, could be plausibly justified as innovations that improved Google's product and the experience of its users. In other words, Google commercial strategy was proven not to be "on balance, demonstrably anticompetitive", since providing direct answers in search results instead of just 10 blue links on a page, rather than being an unlawful conduct, was deemed as the result of a product design change undertaken with a legitimate business justification. ${ }^{8}$

In China, also, an antitrust case against the most popular search engine Baidu, accused of strategic demotion of another service (RenRen), was closed for lack of antitrust harm; ${ }^{9}$ in a 2012 ruling on a suit brought

\footnotetext{
${ }^{5}$ See also Valeria Falce and Massimiliano Granieri, "Searching a Rationale for Search Neutrality in the Age of Google", in Concorrenza e comportamenti escludenti nei mercati dell'innovazione, eds. Giuseppe Colangelo and Valeria Falce (Il Mulino, 2017), Cap. IV.

${ }^{6}$ Torsten Körber, "Common Errors Regarding Search Engine Regulation - and How to Avoid Them", European Competition Law Review 36, no. 6 (2015); Andrea Renda, "Searching for Harm or Harming Search? A Look at the European Commission's Antitrust Investigation against Google", CEPS Special Report, No. 118 (September 2015); Michael A. Carrier, "Google and Antitrust: Five Approaches to an Evolving Issue", Harvard Journal of Law \& Technology Occasional Paper Series (2013); David A. Crane, "Search Neutrality and Referral Dominance", Journal of Competition Law and Economics (2012): 459-468.

${ }^{7}$ An account of the antitrust issues that involve Google is provided by Michael A. Carrier, "Google and Antitrust: Five Approaches to an Evolving Issue", Harvard Journal of Law \& Technology Occasional Paper Series (2013).

${ }^{8}$ See Statement of Edith Ramirez, Julie Brill and Maureen K. Ohlhausen regarding the Google Investigation, at https://www.ftc.gov/news-events/pressreleases/2015/03/statement-chairwoman-edith-ramirez-commissioners-julie-brill. The FTC investigation covered some issues besides Google's use of Universals. These issues included "scraping", Google's AdWords API, and standard essential patents. The aspect of the investigation that drew the most attention concerned Google's use of Universals. See Michael A. Salinger and Robert J. Levinson, "The Role for Economic Analysis in the FTC's Google Investigation”, unpublished manuscript available at http://www.law. northwestern.edu/ (last visit, July 7, 2017).

9 See Tong Shu, "Reflections on Baidu Monopoly Litigation: Comments on Renren v. Baidu", China Patents \& Trademarks 1 (2010): 66.
} 
against Google by shopping comparison site Buscapé (claiming that Google favoured its own shopping results over those of third-party sites), a Brazilian court decided that "nothing prevents [Google], in the conduction of its profit corporate business, from developing and using a tool (algorithmic formula) that returns results to a user query in Google search in a display order dictated by Google's quality and relevance criteria”.

Recently, in July 2015, Taiwan's Federal Trade Commission closed a two-year investigation and concluded that Google's search display practices "could be seen as providing convenience to users and in line with users' benefits", and denied that such practices could constitute an anticompetitive refusal to deal. ${ }^{10}$

\section{The European response}

After the US Federal Trade Commission dealt with search design policy in 2011 and 2012, the EU made a step further in Spring 2015, then in Summer 2016 and last on June 2017, when the final decision was eventually adopted.

On April 15, 2015, the European Commission issued a statement of objections (also SO) against Google after five years of investigations and three commitment proposals. ${ }^{11}$ The alleged violation concerns the disruptive service of Google shopping that drastically changed the internet search and the advertising markets as well as the modus operandi of the competitors therein. According to the Commission, Google, holding a dominant position on the general search engine market, systematically granted preference to results linked - or in any way related - to entities with whom

\footnotetext{
${ }^{10}$ See Andrea Renda, "Searching for Harm or Harming Search? A Look at the European Commission's Antitrust Investigation against Google”, CEPS Special Report, No. 118 (September 2015), text accompanying Note 47 and "Taiwan regulator finds no antitrust infringement in Google's search, Play Store practices", by Joy C. Shaw, 5 August 2015, and http://www.ftc.gov.tw/ upload/cb6a6873-2c93-4a51-a97c-b0e04277afbe.pdf.

${ }^{11}$ See European Commission, "Antitrust: Commission probes allegations of antitrust violations by Google" (30 November 2010) (http://europa.eu/rapid/press-release_IP-10-1624 en.htm?locale=en); European Commission - Press release, "Antitrust: Commission sends Statement of Objections to Google on comparison shopping service; opens separate formal investigation on Android", Brussels, 15 April 2015 (http://europa.eu/rapid/press-release_IP-15-4780_ en.htm). See also the Commission's memo (http://europa.eu/rapid/press-release_MEMO-154781_en.htm). For an insight analysis, Renda, "Searching for Harm or Harming Search? A Look at the European Commission's Antitrust Investigation against Google".
} 
Google has commercial relations, irrespective of their actual relevance to the query of the user, thus infringing article 102 TFEU. ${ }^{12}$

In 2016, the European Commission started a new and related proceeding against Google's parent company, Alphabet, questioning the algorithm, its setting and functioning as expression of an abusive strategy engaged by Google in the general search markets. The Commission intends to investigate the way in which Google displays its own comparison shopping service and that of competitors in its general search results. The initiation of proceedings does not mean that the Commission has made a definitive finding of an infringement but merely signifies that the Commission will deal with the case as a matter of priority. ${ }^{13}$

In 2017 the European Commission released its final decision, concluding that Google has abused its market dominance as a search engine by giving an illegal advantage to another Google product, its comparison shopping service, and as a consequence fining Google with a whooping $€ 2.42$ billion for violation of $\mathrm{EU}$ antitrust rules.

Of course, under the EU antitrust framework, an antitrust concern may arise as and to the extent that competition online is feeble and market power is persistent, if not stable. In the Commission's reasoning the charge is technically for discrimination and the criteria set under art. 102 TFEU are met, since:

1. Google holds a dominant position in the market for general search services in the EEA;

2. As a dominant undertaking, Google shall bear the special responsibility not to further compromise the level of competition nor to undermine innovation in the market;

3. The conduct consisting in positioning and displaying more favourably, in its general search results pages, its own comparison shopping service vis-à-vis competing comparison shopping services amount to a discriminatory conduct in itself in violation of article 102 TFEU.

From the European Commission press release, it results that Google is dominant in general internet search markets in all EEA countries since 2008, except in the Czech Republic where the decision has established

\footnotetext{
${ }^{12}$ Joaquin Almunia, Press conference, Statement on the Google investigation, Brussels, 5 February 2014 (http://europa.eu/rapid/press-release_SPEECH-14-93_en.htm).

${ }^{13}$ See http://ec.europa.eu/competition/elojade/isef/case_details.cfm?proc_code=1_39740.
} 
dominance since 2011. This assessment is based on the fact that Google's search engine has held very high market shares in all EEA countries, exceeding $90 \%$ in most. It has done this consistently since at least 2008 , which is the period investigated by the Commission. There are also high barriers to entry in these markets, in part because of network effects: the more consumers use a search engine, the more attractive it becomes to advertisers. The profits generated can then be used to attract even more consumers. Similarly, the data a search engine gathers about consumers can in turn be used to improve results.

Regardless of its special responsibility, the decision states that no equal treatment was reserved to the other market players. Vice-versa Google gave its own comparison shopping service an illegal advantage, providing a prominent placement in its search results only to its own comparison shopping service, whilst demoting rival services.

Google's illegal practices have had a significant impact on competition between Google's own comparison shopping service and rival services.

Given Google's dominance in general internet search, its search engine is an important source of traffic. As a result of Google's illegal practices, traffic to Google's comparison shopping service increased significantly, whilst rivals have suffered very substantial losses of traffic on a lasting basis. Since the beginning of each abuse, Google's comparison shopping service has increased its traffic 45-fold in the United Kingdom, 35-fold in Germany, 19-fold in France, 29-fold in the Netherlands, 17-fold in Spain and 14-fold in Italy. Following the demotions applied by Google, traffic to rival comparison shopping services, on the other hand, dropped significantly. For example, the Commission found specific evidence of sudden drops of traffic to certain rival websites of $85 \%$ in the United Kingdom, up to $92 \%$ in Germany and $80 \%$ in France. These sudden drops could also not be explained by other factors. Some competitors have adapted and managed to recover some traffic, but never in full. In combination with the Commission's other findings, this shows that Google's practices have stifled competition on the merits in comparison shopping markets, depriving European consumers of genuine choice and innovation. ${ }^{14}$

\footnotetext{
${ }^{14}$ See http://europa.eu/rapid/press-release_IP-17-1784_en.htm.
} 


\section{Framing the problem}

While Google's ranking and display of certain types of search results are organised in a way that is specifically oriented to satisfy consumer attention and interests, in the decision the Commission proves that such search design policy has enormously diverted traffic from competition services, thereby foreclosing competition.

However, reading through the press releases and the memoranda that so far the Commission has made publicly available, there is a preliminary issue to address in order to correctly frame the problem. ${ }^{15}$

The charge against Google search options is one of "search design policy": in fact, what is questioned is "how" Google allocates its space on its general search results pages. On the other hand, the algorithms used by Google to produce and display its results - including those that may have the effect of lowering a number of comparison shopping services in the Google search ranking - are unquestioned and even confirmed. ${ }^{16}$ The Commission decision does not object to the design of Google's generic search algorithms or to demotions as such, nor to the way that Google displays or organises its search results pages (e.g. the display of a box with comparison shopping results displayed prominently in a rich, attractive format). ${ }^{17}$

As known, charges against Google originate from complaints made by a number of companies (not only direct competitors of Google, but also publishers, specialised ecommerce websites and others). They insist on the fact that Google distorts results, so that after the user launches a query, the results include not just blue links that direct users to other websites, but also informational content that, in some instances (or even "systematically", as the Commission claims), comes from Google services. ${ }^{18}$ In this way, so the argument goes, users are unnaturally guided to Google's services and sites at the expense of competitors, which will lose traffic, attention and money, and will eventually exit the market. In other words, the

\footnotetext{
${ }^{15}$ See well before the adoption of the Decision, Torsten Körber, "Common Errors Regarding Search Engine Regulation - and how to avoid them”, European Competition Law Review 36 (2015); Valeria Falce and Massimiliano Granieri, "La search neutrality tra regolazione e abuso di posizione dominante", Mercato, Concorrenza e Regole (2016): 289.

${ }^{16}$ Valeria Falce, "Digital Disruption, Innovation and Competition Law. How the Google Shopping Case is Fitting the Framework", Italian Antitrust Review 3 (2015): 165.

${ }^{17}$ See http://europa.eu/rapid/press-release_MEMO-17-1785_en.htm.

${ }^{18}$ About the evolution of Google's results page since 2006 (when results pages showed just organic results and keywords ads), see Eric Goldman, "Revisiting Search Engine Bias", William and Mitchell Law Review 38 (2011): 96-102.
} 
accusation is that Google used its alleged dominance in Internet search to improve its position in related services that Google offers, such as shopping results, local results, or maps, etc. ${ }^{19}$

To put it simpler, the allegation is not about "whether" the results provided by a search engine shall be the plain and automatic output of a given search algorithm. It is about the fact that Google shall make available space on its general search results pages to its competing comparison shopping service (among which Kelko, LeGuide, Shopping.com, Nextag and Twenga, 7pixel, Axel Springer, Ceneo, Beslist) under the same conditions, and so notwithstanding the limited amount of space available on the general search results pages.

One can seriously wonder whether shopping results, local results or maps are really distinct services (for antitrust purposes) from other search outcomes. Each type of result, after all, is meant to answer a user's query. Indeed, all general search engines have evolved to include their own content like maps, shopping and local information (in addition to links to third-party websites) for the very purpose of answering users' queries more directly rather than only sending users off to other websites to try to find those answers there. ${ }^{20}$

Focusing on transparency and correct information, before the European Commission issued the Statement of Objections, Google had offered a commitment to close a possible case and proposed changes to its search results pages, following a potential alternative path that proved very effective before the Federal Trade Commission when the case was initiated in the United States and quickly settled. The proposal was a possible alternative way a search page can be reframed and organised in order to reinforce transparency and reduce information asymmetry on one hand and in order to show competitors' results.

Of course, evidence is required at all possible interfaces of this legal discourse about the relevant market and market dominance, about abuses and about the possible economic justifications.

In order to fully understand what search manipulation is supposed to be and if it really exists, an explanation of the market for search services is

\footnotetext{
${ }^{19}$ For a different approach, Benjamin Edelman, "Does Google Leverage Market Power through Tying and Bundling?", Journal of Competition Law \& Economics 11 (2015): 365.

${ }^{20}$ For a different view, Edelman, "Does Google Leverage Market Power through Tying and Bundling?".
} 
needed at this point. ${ }^{21}$ At a later stage, following the analysis we will apply the principles of European competition law to Internet search to eventually determine whether Google's technological design of its search engine could plausibly give rise to an antitrust violation and, if so, whether the European competition toolbox will be adequate to remedy.

\section{Market dynamics and competitive pressure}

Google, as a search engine, offers free search services to users, who actually do not pay for what they get. The search engine is powered by the PageRank algorithm. Google's business model is based on selling the attention of the search engine's users to companies willing to advertise their products through Google's results page. ${ }^{22}$ Google as a result monetises the search service by selling advertisements that are displayed on Google's general search results pages. Paid advertisement is the service agreed upon by Google and its business customers. ${ }^{23}$

There is debate around the correct definition of Google's market as two-sided; as a matter of fact, acting as matchmaker between queries and potential answers, and charging only advertisers and not users for the use of its platform, is a multi-sided service that works to balance supply and demand. Sure enough, the ability of Google to charge advertisers and their willingness to pay both depend on how much attention they receive and eventually on the number of users that turn to Google for free searches. The antitrust implications of the two-sided market theory, although fascinating in industrial organisation, are still unclear and its use has been inconclusive before the European antitrust authorities (and by the European Court of

${ }^{21}$ The complexity of search engines and their regulation from a legal perspective comes from the fact that they are technically the interface of many strands. A note of caution, as well as a comprehensive description of how search engines work is provided by James Grimmelmann, "The Structure of Search Engine Law", Iowa L. Rev. 1 (2007): 93.

${ }^{22}$ This position is advocated by Michal Gal and Daniel L. Rubinfeld, "The Hidden Costs of Free Goods: Implications for Antitrust Enforcement”, Antitrust L. J., 80 (2015-2016): 521.

${ }^{23}$ Google sells advertising space on its web properties (as well as third-party web properties), including sponsored search results at the top and right-hand side of its search engine results pages. When a user enters a query, the search engine returns so-called organic, unpaid search results, as well as sponsored (i.e. paid) search results. Google always clearly identifies which search results are paid by placing them at the top and left of the search engine results page and indicating that they are sponsored. Google's organic and paid search results are governed by different algorithms and policies. 
Justice) in recent cases. ${ }^{24}$ Yet, the two-sided markets dynamic is important and its descriptive and normative implications should be part of the framework.

First, it means that Google's search business not only competes with other general and specialised search engines (e.g., Bing, Yahoo!, Amazon, eBay, Twenga, Foundem, Yelp, TripAdvisor), but also with many other platforms attracting user attention with content in order to sell advertising (or, for example, hardware, in the case of Apple), including social media (e.g., Facebook, Instagram, Twitter, SnapChat, Vine, Pinterest, Linkedin, Tumblr), ${ }^{25}$ popular websites (e.g., Yahoo!, MSN, BBC, ESPN), music discovery and streaming applications (e.g., Spotify, Pandora, iTunes Radio), offline and online video and television, offline and online newspapers and many other content providers.

Second, it means that if Google does not continue to offer users the most relevant and useful information as promptly as possible in response to their queries, users will start turning to alternative sources of information. This is especially so as consumers increasingly spend most of their online time on mobile devices, finding information through their virtual personal assistants (e.g., Siri for Apple users, Facebook's M and Cortana for Microsoft) and mobile apps (e.g., shopping and price checking apps like Amazon's and eBay's Shopping and Price Check Apps; local business search and review apps like Yelp's and TripAdvisor's apps; social media apps like Facebook, Instagram, Twitter etc.), rather than web browsing and searching. As TechCrunch recently observed, "[t]he future of search looks a lot like Facebook's M" and "Facebook's M is just one of the contenders for the future of search". ${ }^{26}$ Advertisers, who follow the users, in turn will spend less of their advertising budget on Google's search results pages.

\footnotetext{
${ }^{24}$ European Court of Justice, Judgment of 11 September 2014, MasterCard Inc. v. Commission, C-382/12, EU:C:2014:2201. Recently, Lapo Filistrucchi, Damien Geradin, Eric van Damme and Pauline Affeldt, "Market Definition in Two-Sided Markets: Theory and Practice", Journal of Competition Law \& Economics 10 (2014): 293, have tried to explain the reason courts failed to correctly understand the dynamics of two-sided markets. See also Vincenzo Visco Comandini, "Google e i Mercati dei Servizi di Ricerca su Internet", Mercato Concorrenza Regole XV, 3 (2013): 541-570.

${ }^{25}$ Goldman, "Revisiting Search Engine Bias", 100, has pointed out how Facebook and Twitter do not compete directly with Google for keyword searches and yet they compete with Google for "user mindshare".

${ }^{26}$ See Facebook's Messenger and the Challenge to Google's Search Dominance at http://techcrunch.com/2015/09/07/facebooks-messenger-and-the-challenge-to-googles-search-dominance/.
} 
Google's revenues and profits will thus decline to the extent the quality of its search engine and results declines.

To provide users the most relevant and useful information in response to their queries, search providers need to design their search engines to interpret what a user's intent behind a query is and, based on that interpretation, deliver to the user the most directly responsive information available. Google has to do that for billions of queries every day, ${ }^{27}$ from different users, in different parts of the world, in different cultures and languages. That inherently requires the search provider to determine what it deems relevant and useful information in light of any particular user query, which is an extraordinarily complex process. To illustrate, Google's search algorithms are based on more than 200 factors. ${ }^{28}$ And, because search engines can never know the user's intent with certainty, search engines always deal with probabilities, not absolute truths. ${ }^{29}$ Part of the differentiation between more and less relevant online content also has required search engines to take measures to counter so-called "link farms" and "spam logs", which are web pages designed to manipulate high search engine ranking without any relevant content of their own. ${ }^{30}$

\footnotetext{
${ }^{27} \mathrm{http}: / / \mathrm{www}$. internetlivestats.com/google-search-statistics/.

${ }^{28}$ See, e.g., James Grimmelmann, "Some Skepticism about Search Neutrality", in The Next Digital Decade, eds. Berin Szoka and Adam Marcus, 435, 455 (2010), available at http://james.grimmelmann.net/files/articles/search-neutrality.pdf; see also http://www.google.com/insidesearch/ howsearchworks/algorithms.html.

${ }^{29}$ While truth tends to be the same, almost by definition, probabilities change and the algorithm that provides results needs adjustments to constantly reflect modifications in the magmatic informational base of the search engine and to meet users' expectations. There is evidence of the functioning of search services also in the Stanford patents that cover the search algorithm. Absence of a normative standard for truth in searches prevents a judgement of true or false with respect to results. On the absence of such normative standard see Marina Lao, "Neutral' Search as a Basis for Antitrust Action?", Harvard Journal of Law \& Technology Occasional Papers Series 3 (2013). If search results are "credence" good, as some authors have suggested, then there is also an inherent difficulty for the provider (and not only for the user) to measure ex post the utility of the information retrieved. The argument of credence good (although against Google) was firstly used by Mark R. Patterson, "Google and Search-Engine Market Power", Harv. J. L \& Tech, July 19, 2013.

${ }^{30}$ See, e.g., http://searchengineland.com/google-forecloses-on-content-farms-with-farmer-algorithm-update-66071. The need to change the results came also from the liability of Google as service provider, which requires intervention when, for instance, a website posts content in violation of third parties' copyright or when illegal content is displayed. Google itself recognised that such activities are carried out and that websites that systematically infringe copyright are downgraded in the rankings; see the blogpost of Google at the following URL: http://googlepolicyeurope. blogspot.co.uk/2014/09/dear-rupert_25.html (last visit, August 28, 2015).
} 
Evidently, the way the service is organised and works is good for users. Being otherwise, consumers would have the freedom to switch easily to other search engines or services that can provide answers, exactly as they did when Google first appeared on the market and displaced incumbents. In this respect, competition is really still one click away and even more so: switching costs for users are negligible. ${ }^{31}$

Even after Google's entry, online search has been characterised by significant changes and innovations. One improvement in online search has been the evolution towards providing users direct answers to their queries, in addition to the more traditional links to other websites. It is largely this integration and evolution in the design of search engines that has prompted the antitrust complaints against Google by some of its competitors. Yet, such vertical integration and product design is typically procompetitive, for example, because it reduces clicks and search time for users, and is more directly responsive to their questions. What's more, it is not just Google that has adopted this design. All search engines follow that model, including Yahoo! and Bing. This evolution within the industry confirms that the design is perceived as user-friendly and makes the service more attractive. For example, as the head of Yahoo!'s search strategy already observed in this regard in 2009: “[p]eople don't really want to search ... Their objective is to quickly uncover the information they are looking for, not to scroll through a list of links to Web pages". ${ }^{32}$ Without such constant improvement and evolution, a search engine will quickly fall out of favour with users.

The internet is an expanding universe, with content that changes continuously and is continuously enriched and modified. Moreover, website administrators are constantly active to improve visibility of their sites, through search engine optimisation (SEO) techniques. ${ }^{33}$ In a sense, all

\footnotetext{
${ }^{31}$ Lao, "Neutral' Search as a Basis for Antitrust Action?", 7 (“Unhappy Google users can instantly switch to another search engine, such as Bing or Yahoo!, without incurring any penalties or costs"). In this respect, the accusation that Google preset its search engines as default system on browsers sold by OEM in computers and other devices seems exaggerated; changing the default engine is easy and inexpensive even for the least experienced internet user. On low switching costs in digital environment as opportunity for new entrants to solve informational needs, Goldman, "Revisiting Search Engine Bias", 101.

${ }^{32}$ James Niccolai, "Yahoo! Vows Death to the '10 Blue Links"', PCWorld (May 19, 2009), http:// www.pcworld.com/article/165214/yahoo_vows_death_to_blue_links.html.

${ }^{33}$ Otherwise, the internet would be dominated by companies with powerful and smart IT departments, displacing smaller companies with superior products or services, but reduced IT resources to gain visibility on the web.
} 
internet users are responsible for its continuous modifications and Google is responsive to changes ${ }^{34}$ and constantly offers new features to its search engine to improve it. ${ }^{35}$ In this perspective, any strategy of attraction and retention is based absolutely on the quality of the service provided (valuable not per se, but for the ability to then sell advertising opportunities), which in the case of internet services is relevance. If results are not relevant, users move away with just a click of their mouse, traffic slows down and the ability to sell their attention and traffic decreases.

\section{Search design and market boundaries}

These preliminary issues about the services provided by Google require a little side discussion regarding market definition as a necessary step in antitrust analysis. Although this specific topic will also be addressed later, it is necessary to touch upon it here to complement the explanation of search bias and to interpret some of Google's behaviours.

Complainants have argued that Google holds a dominant position in the market for general search. A position that appears to indicate the complainants believe search engines are the only viable solution to the information retrieval problem. ${ }^{36}$ This same argument leads to the conclusion that Google is the gateway to the internet. This position ignores important facets of online markets.

Online searches today are possible in different ways. First of all, users typically spend more time using their smartphone than their PCs or tablets. This is important because smartphone users have access to information through their virtual personal assistants, such as Siri for Apple users and Cortana for Microsoft, Similarly, Apps are now bringing vigorous competition to search services in a more specialised and pervasive way; providers of vertical services (such as price-matching, online ticketing, hotel reservations, etc.) all have their apps available on a number of platforms. Third, social media platforms, such as Facebook or Twitter, are becoming

\footnotetext{
${ }^{34}$ Google, for example, makes more than 500 changes to its algorithms every year (see Grimmelman, "The Structure of Search Engine Law", 455).

${ }^{35}$ See http://www.google.com/insidesearch/howsearchworks/algorithms.html.

${ }^{36}$ Authors have expressed extremely different views about Google's dominance. According to Edelman, "Does Google Leverage Market Power through Tying and Bundling?", 16 (quotes from the original manuscript), Google has significant market power in the search market. More dubitative is Lao, "Neutral' Search as a Basis for Antitrust Action?", 6. As a matter of fact, a clear showing of Google's dominance is missing.
} 
active in facilitating access to information for their users. ${ }^{37}$ If it is true that Google is complementing its services with direct content, it is no less true that social networks are also becoming a source of information. ${ }^{38}$

Increasing inter-platform competition seems to characterise retrieval of information over the internet. These dynamics compel us to ask a number of questions. First of all, what is the correct current perimeter of the market? Second, and most importantly to our purposes, what are the legitimate strategies of any firm (and, particularly, a dominant firm) if the competitive scenario is changing rapidly? Third, even if Google has to interact with results to ensure relevance, is this something that can qualify as bias or is it just part of the inevitable way each search engine works? Providing a final answer to these questions goes beyond the purpose of this article, but contributing to the correct reading and qualification of the framework in which to answer them is precisely its aim.

As to the first question, the search results Google offers are not standalone free goods; no one could afford to provide such free results without some form of monetisation. At a minimum, the market definition should include the market for ads as the one that is generating revenues and not be limited to the search service as such. Some authors have shown that companies allocate their budget for advertising differently today, moving resources from online to offline services. This circumstance would add a further level of complexity in the definition of the market, as it somehow requires taking into account the substitutability of services. Offline advertising is putting pressure on online advertising services, not so much as to conclude that there is only one relevant market for advertising, but enough to admit that competitive forces are unexpectedly at work and can become an external constraint to the behaviour of firms in online services.

If actual and potential competition is stronger than expected, due to offline services and to an expanded list of online services, any firm in the market for searches would need to reconsider its strategies by rationally improving quality as a primary goal. Excluding competitors would be a naïve objective when the whole set of competitors proves to be quite big and diverse (ranging from alternative search engines, to online travel agencies,

\footnotetext{
${ }^{37}$ Goldman, "Revisiting Search Engine Bias", 100, has pointed out how Facebook and Twitter do not compete directly with Google for keyword searches and yet they compete with Google for "user mindshare".

${ }^{38}$ Andrew Odlyzko, "Network neutrality, search neutrality, and the never-ending conflict between efficiency and fairness in markets", www.ssrn.com.
} 
just to name a few). But adjusting product design in some instances can qualify as a legitimate reaction to increasing competitive pressure and not necessarily as abuse. ${ }^{39}$

Indeed, as also explained in a post by Google's Senior Vice President for Google Search Amit Singhal, ${ }^{40}$ Google evolved its model not just by providing a set of links on a flat web page, but by bringing to the results the information users would likely need when Google was confident it could display a good answer to the user's question. In the older format, reaching this information would have required navigating to one or more links. From an antitrust standpoint, this evolution in product design, and new models within this industry, should challenge the traditional view regarding dominance, since market definition cannot overlook the variety of search opportunities and the competitive pressure put on Google by alternative services. ${ }^{41}$

Overall, what Google does is just improving the user experience, by shortening the distance between the query and the answer, when there is a strong likelihood that Google can provide directly, in the search results, what the user is looking for (e.g., the price of a plane ticket). In doing so, Google does not change the nature of the service, which is based on the predictive power of the algorithm and on the quality of results. Because of the nature of the internet and the extreme variance of users' expectations, Google has to interact with results through its algorithm and organise answers in a way that always tentatively matches users' preferences. If the algorithm learns relationally by users' choices, this is part of Google competing on the merits, not its fault or its liability.

Moreover, the shift from the "ten blue links" model to an integrated web service entails more editorial responsibility; quality (which means, relevance) matters more now than in the past. Again, the fact that Google

\footnotetext{
${ }^{39}$ See David Crane, "Search Neutrality as an Antitrust Principle", Public Law and Legal Theory Working Paper Series 256, 6 (2011) ("Unless the search engine is to remain stuck in the ten blue links paradigm, search engine companies must have the freedom to make strategic choices about the design of their services, including the decision to embed proprietary functions traditionally performed by websites in the engine's search properties"). See also Lao, "Neutral' Search as a Basis for Antitrust Action?", 11 ("Preventing general search engines from organically transforming themselves would only artificially interfere with the natural process of competition that is occurring").

${ }^{40}$ See http://googleblog.blogspot.it/2015/04/the-search-for-harm.html (last visit, August 28, 2015).

${ }^{41}$ Crane, "Search Neutrality as an Antitrust Principle", 5, questions the opportunity to now distinguish search and content, if eventually also a results page is a webpage that carries vertical information to users.
} 
is also active in some vertical services does not alter the substance of the analysis. ${ }^{42}$ Failure to provide relevant results would doom Google, just like any other provider of search services. If this holds true, systematic preference of Google's vertical services on Google's page of results is economically irrational. ${ }^{43}$

Google and all other search engines only implicitly promised (as a condition of survival and as a value proposition to users) to do their best to identify, rank and display what they believe is the most relevant information in response to a user query. ${ }^{44}$ And, since there is no single truth or single best or neutral way to rank or display search results, search engines in fact compete with each other exactly by differentiating themselves with respect to those aspects. ${ }^{45}$ Incorporating content in search results is a form of differentiation that search engines use to compete and provide more relevant answers to users. ${ }^{46}$ In other words, ranking is the most significant way in which search engines can compete with each other. Thus, restricting the manner an engine ranks results would risk eliminating that search engine's most significant way to innovate and compete by differentiating itself from rival search engines.

Of course, as the search results market is two-sided, there are two sets of customers, which are consumers as users and merchants as advertisers. In the merchants' perspective, there are many options to attract customers other than advertising on the comparison shopping services that as such do allow direct purchasing. Merchants can attract traffic by appearing on merchant platforms (as Amazon, eBay, AliExpress, Etsy and Rakuten). Besides, they can attract traffic by purchasing advertisements on merchants' platforms (such as Amazon Sponsored Products and Amazon Product Ads).

\footnotetext{
${ }^{42}$ This does not mean that Google does not become a competitor for providers of vertical searches; the shift from a mere search engine to a website (something referred to as "portalization") changes the nature of the relationships between Google and third-party websites (see Goldman, "Revisiting Search Engine Bias", 103).

${ }^{43}$ This argument was obviously advanced by two Chicago scholars, namely Robert H. Bork and Gregory G. Sidak, "What Does the Chicago School Teach about Internet Search and the Antitrust Treatment of Google", Journal of Competition Law and Economics 663 (2012): 10.

${ }^{44}$ As Crane, "Search Neutrality as an Antitrust Principle", 10, pointed out, there is no need to invoke neutrality to admit that a search engine should, under given circumstances, be liable for "intentionally interfering with their rivals' hits in search results".

${ }^{45}$ This point is made also by Torsten Köber, "Common Errors Regarding Search Engine Regulation - and How to Avoid Them", European Competition Law Review 36 (2015): 239-243.

${ }^{46}$ Additionally, it has to be considered that not all OneBoxes of Google contain Google's own content. In some instances, the information comes from other websites, such as Wikipedia.
} 
Online search advertising platforms are also considered by merchants seeking to attract traffic. Merchants are increasingly advertising on social networks, banners and sidebars, mobile apps video ads, and internet radio ads. It seems from the records that the relevant markets have not been defined taking into due account both sides of the demand.

\section{Is article 102 TFEU a sound solution?}

There might still be room to argue that a legitimate market reaction amounts to abuse when coming from a dominant firm and that such abuse is the result of a voluntary and aforethought strategy. Thus, search design could reveal an exclusionary practice carried out by Google.

The charge that Google's search policies are discriminatory and exclusionary, and aimed at systematically and willfully favouring Google's own services, requires an investigation about facts. But in order for such conduct to be an antitrust violation evidence that such search policies are against antitrust principles and, as to the results, significantly distort the competitive process is also required. If this evidence is not carefully provided, there is the serious risk that an antitrust enforcement action ends up being a claim of strict liability against Google, not for its alleged actions (abuses), but for its very position on the market, which was not obtained (nor maintained) through exclusionary practices, but is the consequence of technological innovations. ${ }^{47}$ One aspect that should be given prominent weight is the fact that search services are free and although there might be instances in which free goods have negative welfare effects, shortcuts to antitrust liability should be avoided. ${ }^{48}$

As far as European Union law is concerned, the relevant provisions are those of article $102 \mathrm{TFEU}$, concerning the abuse of a dominant position. ${ }^{49}$

\footnotetext{
${ }^{47}$ It should be recalled that when Google first appeared on the market there were already search engines which were dominant. Other search engines (and other solutions to retrieve information) are also available today and this should be sufficient evidence that there are no significant barriers to entry, that Google proved superior with respect to competitors and that the market is evolving faster than any perspective of antitrust enforcement.

${ }^{48}$ Gal and Rubinfeld, "The Hidden Costs of Free Goods: Implications for Antitrust Enforcement" (page 3 of the original manuscript), propose a more sophisticate reading of the welfare effect of free goods and one of the fields where such effects are investigated is that of free internet search.

${ }^{49}$ Alike Lao, "Neutral' Search as a Basis for Antitrust Action?", 4, we do not contend that there is no antitrust theory of liability for search bias and, in this respect, we reinforce our position about the differences between U.S. and European competition policies. We rather assume that search bias could be analysed under the paradigm of abuse of dominant position and advocate an orthodox application of its elements.
} 
The institutional framework of adjudication (or enforcement) should be built on that specific provision, on the practice of the European Commission and, importantly, on its interpretation by the European Court of Justice.

There is no need to discuss in detail the rationale behind article 102 or its logic. Suffice it to say that, under European antitrust principles, the dominant firm on the market has a special liability and some behaviours, which might be perfectly acceptable and tolerable in any other market condition, become forbidden when acted upon by a player with significant market power. Scholars and judges have been carefully repeating that it is not the dominant position per se that is unlawful, but its abuse (and some practices used to gain a dominant position). The implications of this statement are crucial in terms of the standard for evaluating the behavior of a dominant firm.

Times seems ripe to advance an effect-based approach and a more economically-oriented analysis of market conducts to be evaluated under article 102 in analogy of the recent trends toward article 101 case assessments. Under European antitrust rules, article 101 concerns restrictions by two or more firms that engage in agreements, associations, decisions of associations or concerted practices in restraint of competition. Article 101 states that behaviours by two or more companies shall be suspect either because by their very nature they foreclose competition (by object) or because they can have, as a consequence, the hampering of the competitive process (by effect).

Unlike article 101, there are no redeeming conditions for the abuse of dominant position and, apparently, there is no room to distinguish restrictions which are harmful for competition according to their actual effects on the market and those which can be considered unlawful by object (no further evidence being requested). Yet, there is general agreement about the fact that conducts under article 102 can also be subject to different evaluations depending on their restrictive potential or their actual restrictive effects on the relevant market.

In fact, at least one author has recently recalled that the application of article 101 by the European Commission has been progressively in the sense of a massive use of the notion of restriction by object, an interpretive option with serious (but questionable) practical implications. ${ }^{50}$ First, it allows speed and savings in terms of administrative costs, for the authorities (and

\footnotetext{
${ }^{50}$ Ginevra Bruzzone, "Le restrizioni per oggetto nella giurisprudenza della Corte di giustizia: alla ricerca di un approccio sistemico", Paper presented at the V Antitrust Symposium, Trento (April $17,2015)$ (unpublished manuscript on file with the author).
} 
the Commission) do not need to invest in intensive investigations and the collection of quantitative and qualitative evidence regarding the impact of conduct in the relevant market. Second, it fosters predictability and, related to that, it increases deterrence.

However, this attitude of the Commission has been criticised and the European Court of Justice has shown dissatisfaction in recent cases (Cartes Bancaires), suggesting a limiting approach to the notion of restriction by object, for the antitrust enforcement to be consistent with the European antitrust framework. Otherwise, the enforcement strategy of the Commission could turn into a surreptitious way to release the Commission itself from the burden of proving actual effects on the market even in those cases (and the Google case is certainly among those) where it is all but apparent that such effects are harmful. It might well be that indulgence to an antitrust enforcement reliant on the "by object", rather than effectbased tests would risk Type I errors (false positives), deterring procompetitive, innovative behaviour.

Eventually, there are at least two additional arguments that would recommend an effect-based analysis, ${ }^{51}$ in a charge of abuse of dominant position by Google. First, the free nature of the service for one class of internet users (those using Google services). Second, the complex nature of the market at stake, which displays significant differences with respect to traditional situations in which standard antitrust analysis applies smoothly.

As to article 102 TFEU, since Hoffmann La Roche, the enforcement of the abuse of a dominant position has been made dependent on a positive showing that the abuse refers to conduct that has the effect of harming the maintenance or the increase in competitiveness in the market. ${ }^{52}$ More recently, advocate general Colomer, in his opinion on Glaxo, supported the view that there should not be per se violations under article $102,{ }^{53}$ and, following the Court in Post Danmark, an evaluation of actual or potential effects on competition is always in order. ${ }^{54}$ Thus, an antitrust based only on heavy reliance on the nature of the conduct itself, and not on its effects,

\footnotetext{
${ }^{51}$ For a more economic approach, based on an effect based analysis, see the Report by the EAGCP, "An economic approach to Article 82" (July 2005); European Commission, DG Competition discussion paper on the application of Article 82 of the Treaty to exclusionary abuses (December 2005). ${ }^{52}$ Judgment of the Court of 13 February 1979, Hoffmann-La Roche \& Co. AG v Commission of the European Communities, C-85/76, EU:C:1979:36, paragraph 91.

${ }^{53}$ Opinion of the advocate general Colomer, Glaxo, C-468/06 and 478/06, EU:C:2008:180.

${ }^{54}$ Judgment of 27 March 2012, Post Danmark A/S v. Konkurrencerådet, C-209/10, EU:C:2012:172, paragraphs 24 and 39 .
} 
is not consistent with European principles of antitrust, both in article 101 and in article 102 cases. ${ }^{55}$

As far as search design is specifically concerned, to the extent that it is interpreted and construed as an exclusionary and/or discriminatory practice, in the abstract it may fall under article 102, particularly if the charged firm has market power. ${ }^{56}$ But this is not enough to conclude that there is abuse and, consequently, to affirm antitrust liability. It only means that article 102, if ever, is the correct normative framework for the analysis. A further step is necessarily required, namely a serious and comprehensive consideration of the effects of Google's practices, in order to show that its choices, regardless of Google's intent, harm competition (and not just competitors, or some of them) and reduce consumer welfare, which seems to a be a compelling ingredient of the analysis. ${ }^{57}$

When discussing the effects of Google's search practices, users' experiences and perceptions must be reinserted in the investigation, not just for the sake of complexity or to indulge econometric fascinations, ${ }^{58}$ but to make sure antitrust policy is not diluted into a quicker, but blunter mechanism to protect complainants even when conduct is beneficial to users. ${ }^{59}$

We argue that in dynamic, high-tech industries, the enforcement of antitrust rules that do not focus on effects cannot possibly be reconciled with

\footnotetext{
${ }^{55}$ In reviewing the Commission's decision in Judgment of 12 June 2014, Intel Corp. v. Commission, T-286/09, EU:T:2014:547, the Court recalls the chance that restrictions by object are not considered unlawful if they entail efficiencies or are objectively justified. The principle is crystal clear in the U.S.; see Crane, "Search Neutrality and Referral Dominance", 9 ("liability should only attach to those acts that have anticompetitive effects - those acts that create, enhance, or preserve market power").

${ }^{56}$ This allegation is vigorously contested by Google. We provide here arguments that might lead to a different reading of search design.

${ }^{57}$ We find support to our position in the recent opinion of the European Court of Justice in Judgment of 6 October 2015, Post Denmark A/S, C-23/14, EU:C:2015:651, where the judges state that "it is nevertheless open to a dominant undertaking to provide justification for behaviour liable to be caught by the prohibition set out in Article 82 EC [now 102]" (paragraph 47).

${ }^{58}$ Cristoforo Osti, "Ma a Che Serve l'Antitrust?", Il Foro Italiano V (2015): 121, has recently remarked that a vigorous antitrust enforcement is not just about quantitative marginal analysis, but also a tool for protecting democracy and increasing social cohesion.

${ }^{59}$ In the United States, the option of regulating search engines (and Google in particular) was advocated by Orel Bracha and Frank Pasquale, "Federal Search Commission? Access, Fairness, and Accountability in the Law of Search", Cornell L. Rev. 93 (2008): 1149. See also Frank Pasquale, "Internet Nondiscrimination Principles: Commercial Ethics for Carriers and Search Engines", The University of Chicago Legal Forum (2008): 1. The solution has been strongly criticised both on legal and technical grounds. When referred to Europe, the perspective of regulating search engines will have to find its legal basis.
} 
any statement about incentives to innovation which competition should preserve and reinforce. Any firm with commercial success would be frozen in its attempt to be more innovative and to respond to greater competition, even if its reaction resulted in superior products or services for consumers. This is particularly so in a market whose boundaries are hard to define.

In complex markets, such as internet-based, multisided services, there are no easy conclusions about conduct and no shortcuts to a cheaper antitrust approach. Needless to say, a line of reasoning based on the effects of a behaviour is more difficult and laborious: the more complex the factual situation (such as in dynamic industries), the more rigorous and uncompromising the analysis should be.

If article 102 is the correct framework to assess the potential anticompetitive effects of search bias, a number of questions is in order and, among those, whether search strategies as described in paragraph 4, retro, can be considered discriminatory at all and, if that is the case, which interests should be taken into account in order to decide the harmful nature of such strategies and their anticompetitive effects.

The description of Google's search design provided arguments to conclude that the allegedly exclusionary conduct is the industry standard and that it is used by all the major competitors in this space as it offers significant user benefits. Condemning $a$ firm for that behaviour would automatically translate into a decision that that firm cannot stay in the market; but any decision that reduces competitors, rather than increasing their numbers, would turn antitrust policy on its head.

As should be clear by now, search design is not the name of an antitrust misconduct, but the very way information is processed and organised to provide users with an acceptable search experience. Moreover, a claim of neutrality can only be stated in the abstract and never become an objective milestone to define competitive behaviours, since paradoxically neutrality - in its purest form - would require that the information is left as it is found, with no added value for users (and, in a two-sided perspective, for advertisers). One might even say that users do need bias in the search, ${ }^{60}$ which is just a more impressive way to say that relevance and neutrality are at odds and since users need relevant results (not just results), neutrality

\footnotetext{
${ }^{60}$ Renda, "Searching for Harm or Harming Search? A Look at the European Commission's Antitrust Investigation against Google", 14 ("there are reasons to believe that a neutral search engine would be hated by consumers").
} 
cannot be part of the analysis if not resulting in clear and flagrant discrimination of all competitors. ${ }^{61}$

Some may argue that even if a behaviour is a common industry practice, not just the competitive strategy of a dominant firm, it becomes anticompetitive once adopted by a firm that is dominant or as a firm becomes dominant. But this line of argument misses the point. The fact that a product design is an industry practice, and has been adopted by firms that do not have a dominant position, is strong if not presumptive evidence that the product design is procompetitive rather than anticompetitive, especially in a dynamic high-tech industry where firms can adapt quickly. And a dominant firm, too, has the right and should be permitted to pursue procompetitive product designs and business practices even if the product designs and practices are so competitive that they might harm rivals while benefitting consumers. This reinforces the case for effect-based analysis, ${ }^{62}$ since only behaviours that in actual terms harm the competitive process can be considered unlawful. The qualification of the conduct (as lawful or unlawful) follows the analysis; it should not be its starting point.

As to the assessment of the effects, any antitrust analysis must be supported by evidence especially where the enforcement action is directed at product design (rather than, for example, contractual arrangements). So far, despite the European Commission's five years investigation and a Statement of Objections, there seems to be a dearth of evidence of such anticompetitive effects.

To the contrary, unlike for example in the Microsoft case where Netscape experienced a dramatic decline in browser share (from $80 \%$ to 20\% between 1997 and 2000) at the same time Microsoft's browser share skyrocketed (from $20 \%$ to $70 \%$ in same time period), ${ }^{63}$ here many of the websites that supposedly would suffer from Google's search engine design (and have been the leading complainants to the European Commission, in addition to Microsoft) have actually been growing substantially and

\footnotetext{
${ }^{61}$ As FTC Chairman Leibowitz has declared, "[a]lthough some evidence suggested that Google was trying to eliminate competition, Google's primary reason for changing the look and feel of its search results to highlight its own products was to improve the user experience".

${ }^{62}$ As Crane, "Search Neutrality as an Antitrust Principle", 8, posits it, "[d]ominant firms may sometimes have special antitrust obligations not shared by weaker rivals, but those obligations should never stand in the way of the firms' ability to innovate". The argument, needless to say, cannot be valid only on one side of the Ocean.

${ }^{63}$ See, e.g., http://www.justice.gov/atr/declaration-rebecca-m-henderson-us-v-microsoft-corporation-state-new-york-ex-rel-v-microsoft.
} 
command a much greater share than Google. For example, local search engine Yelp has grown its revenue by $350 \%$ in the last four years, travel search site TripAdvisor claims it has the Web's largest travel brand and nearly doubled its revenues in the last four years, travel search site Expedia has grown its revenues by $67 \%$ in the same time frame and claims that it is seeing increased traffic from Google, shopping sites like Amazon, eBay and Idealo, lead that segment and have seen tremendous traffic growth in a number of EU member states over the last several years. ${ }^{64}$ Google has a very small share of both travel and shopping searches (e.g., about ten times less than each of Amazon and $\mathrm{eBay}^{65}$ ) compared to these search sites in European member states, including France, Germany and the UK (indeed, Google is among the smallest search sites for travel and shopping in those member states) ${ }^{6}{ }^{6}$ And vocal complainant Axel Springer (owner of the French search engine Qwant) reported recently that "there is a lot of innovation on the search market". ${ }^{67}$ Scholars and policy-makers will no doubt go about trying to collect data to prove their case, but these facts certainly beg the question whether there is even harm to competitors, let alone harm to consumers and competition as a whole.

Apart from quantitative effects, there is a major issue that still needs to be considered in preparation for future quantitative analysis and to bring evidence to the correct institutional framework. To what extent do Google search strategies really disfavour competition, rather than foster it? Coming to one of the points raised in the introduction of this article, one of the questions is to decide what the real aims of European antitrust are and which values are competition rules aimed at protecting in Europe. ${ }^{68}$

If results are not adjusted by Google to ensure relevance (which means, users' preferences) is given prominent value, how could new entrants on the internet gain visibility? If neutrality means aseptic editorial policy or purely unbiased provision of data, what is the guaranty that incumbents are not preferred vis-à-vis newcomers?

\footnotetext{
${ }^{64}$ See also http://googleblog.blogspot.com/2015/04/the-search-for-harm.html. Data from Amazon, for instance, confirm growing revenue figures; see amazon.com, Annual Report, at 69.

${ }^{65}$ See, e.g., http://www.techtimes.com/articles/48976/20150428/unlikely-ally-ebay-backsgoogles-arguments-over-eu-antitrust-case.htm.

${ }^{66} \mathrm{http}: / / g o o g l e b l o g . b l o g s p o t . c o m / 2015 / 04 /$ the-search-for-harm.html.

${ }^{67} \mathrm{See}$ http://www.axelspringer.de/en/presse/Axel-Springer-Digital-Ventures-is-participating-inFrench-startup-Qwant.com_21308881.html.

${ }^{68}$ The question on the final goal of European antitrust has been recently raised by Osti, "Ma a Che Serve l'Antitrust?", 114, comparing US and EU antitrust policies.
} 
There are competitors that are happy with current Google search strategies and there might be potential competitors that would benefit from the fact that relevance - and not subjective and idiosyncratic requests by incumbents - is the main driver of search engines. ${ }^{69}$ If that is the case, then any assertion about Google's conduct being systematically discriminatory, exclusionary and comprehensively harmful for competition should be carefully checked and proven.

Running an effect-based analysis demands a granular approach. Eventually, once a market has been correctly defined and the dominance of Google clearly ascertained, in order for search design to be considered abuse, there needs to be a showing of its impact on the competitive process as a whole and not just on some players. Unless antitrust authority openly explains that the ultimate goal of European antitrust policy is not just control of market power and pursuit of consumer welfare, but also general prophylaxis of conduct, that might appear as unfair. ${ }^{70}$

Nothing in the Google Search saga demands an exemption from antitrust scrutiny (probably not even the free nature of the service), but a blunt use of antitrust as a proxy for market regulation is outside the reach of article 102 TFEU. Forcing the limits of Article 102 to turn an industry-wide practice into an abuse without assessing its effects would cause more harm than any planned benefit eventually provided.

\section{Diversities that matter: The European institutional approach and the antitrust of the digital economy}

As the case of the decade, the Google investigation cannot avoid raising the arguments that are common to the enforcement of antitrust rules in high-technology markets. Every substantive argument about Google needs to be dealt with under the proper institutional framework; as argued at the beginning of this article, while analyses have been provided for the U.S. economic and legal system, a European perspective is still missing and a comparison is compelling.

\footnotetext{
${ }^{69}$ The issue of desirability for newcomers has been raised by Renda, "Searching for Harm or Harming Search? A Look at the European Commission's Antitrust Investigation against Google”, 15.

${ }^{70}$ However, any explanation of this kind would run counter to the recent position of the European Court of Justice expressed in Post Danmark (the dominant firm "may demonstrate that the exclusionary effect arising from its conduct may be counterbalanced, or outweighed, by advantages in terms of efficiency which also benefit the consumer" (paragraph 48).
} 
One such argument is about the timeframe of regulatory intervention. Google was investigated in the United States by the FTC for nineteen months. ${ }^{71}$ The FTC closed the case in 2013. ${ }^{72}$ The European Commission issued a Statement of Objections in spring 2015, after years of investigation, when a proposal for commitments by Google had been on the table for a while. ${ }^{73}$ The case will last months if not years, and in the end, whatever the conclusion, we will ask whether it refers to the market as it was five years ago, as it is now or as it will be in the future. In any event, things will be extremely different and the final decision will affect a situation that will be dramatically modified. ${ }^{74}$

This by no means implies that an antitrust initiative is per se useless. The argument $a b$ inconvenienti does not help to clear up the situation, no matter how difficult the case and how complex its implications. But the institutional approach - that is to say, the way antitrust rules are enforced should be part of the solution, and not the main source of problems. If we accept the idea that the internet and related industries have caused a radical change in the market, insisting on a traditional approach (where time is but one of the variables) sounds contradictory.

European markets are different from the ones in the U.S., but some features of digital markets are the same and they relate more to the technological dimension of the problem than to the economic aspect involved. The way and the speed with which technology evolves yields unexpected

\footnotetext{
${ }^{71}$ As concluded by the Federal Trade Commission, in a press release of January 3, 2013, "Undoubtedly, Google took aggressive actions to gain advantage over rival search providers. However, the FTC's mission is to protect competition, and not individual competitors. The evidence did not demonstrate that Google's actions in this area stifled competition in violation of U.S. law"; available at https://www.ftc.gov/news-events/press-releases/2013/01/google-agrees-changeits-business-practices-resolve-ftc (last visit, August 19, 2015). Criticism on the FTC's decision has been expressed by Frank Pasquale, "Paradoxes of Digital Antitrust: Why the FTC Failed to Explain Its Inaction of Search Bias", Harvard Journal of Law \& Technology Occasional Paper (2013).

${ }^{72}$ Details of the investigations leaked out of the FTC's files in a Freedom of Information Act request. The news comes from "New Details in U. S. Probe of Google", Wall St. Journal (March 20, 2015).

${ }^{73}$ Against the prediction of Albert A. Foer and Sandeep Vaheesan, "Google: The Unique Case of the Monopolistic Search Engine”, Journal of European Competition Law \& Practice 4 (2013): 199 ("Given the high level of cooperation between these authorities in the Google matter, it seems unlikely that the pending investigations will reach significantly different results"), it seems that the European Commission will go its own way with regard to the case.

${ }^{74}$ The negative predictions of Joshua G. Hazan, "Note, Stop Being Evil: A Proposal for Unbiased Google Search", Michigan Law Review 789 (2013): 111, that Google search practices would get rid of competitors in the market for vertical searches if an action is not quickly taken does not seem to be consistent with the current market situation.
} 
changes and these happen everywhere, with the same intensity and at about the same time. One question we cannot postpone is whether the perspective of a long investigation by the Commission (possibly delving into an effect-based analysis) makes sense at all when things change radically in a timeframe that is shorter than an administrative enforcement initiative and the main drive for change is technology, not regulation.

Each complex antitrust case shows some peculiarities that require a cautious approach in generalising problems and solutions. ${ }^{75}$ At the same time, antitrust authorities, policy-makers and scholars have a duty to re-think the institutional framework whenever they are given an occasion to do so.

The case on search design should prompt a reflection about consistency of actions and foundations of antitrust. The Chicago School has brought more economic and quantitative analysis to antitrust and its teachings have enriched the understanding of some market behaviours and conduct. ${ }^{76}$ Scholars now advocate a more technological approach in antitrust analysis, which would demand reinforced attention to the effects of behaviours and decisions, from a technological standpoint, and to dynamic efficiencies. ${ }^{77}$

The European Commission adopted on May 6, 2015 a Communication titled A Digital Single Market Strategy for Europe, where it highlights the pillar for a strategy of growth based on digital technologies. The Commission recalls the principles of Better Regulation to advance its mandate with respect to the Digital Agenda.

In such perspective, search design policy shall be left to the competitive arena until the principle of freedom to compete and win the selection "for" the market prevails. In the light of such principle: a) no market player shall be limited in its capability to design its products in order to win the competition game, meaning that also Google shall be free to provide for tailored results in order to catch both consumers' and advertisers' attention in the market for search results; b) no market player shall be limited in its ability

\footnotetext{
${ }^{75}$ Foer and Vaheesan, "Google: The Unique Case of the Monopolistic Search Engine", 200, incline to believe that Google is a unique case that might require measures going beyond the simple option antitrust/regulation and "consider[ing] all alternatives, including the deliberate use of public resources to maintain effective choice in information sources on the Internet".

${ }^{76}$ Bork and Sidak, "What Does the Chicago School Teach about Internet Search and the Antitrust Treatment of Google", try to apply the Chicago School antitrust teachings to the Google search case. ${ }^{77}$ Rupprecht Podszun, "The More Technological Approach: Competition Law in the Digital Economy", in Competition on the Internet, ed. G. Surblyte (Berlin/Heidelberg, 2015): 101; the original idea was already mentioned in Ibid., "Kartellrecht in der Internet-Wirtschaft: Zeit für den more technological approach”, WuW (2014): 249.
} 
to offer its advertising space on its platform at its own conditions; c) no market player shall be protected in itself or subsidised. ${ }^{78}$

Apart from the traditional regulatory perspective, if the initiation of an antitrust action is considered absolutely necessary in light of the potential effects of Google's conduct, because of the institutional peculiarities of European competition laws and the fast changing features of high technology markets the conclusion can be different from that of a traditional action. In this respect, an alternative and more effective path - one that would certainly spare the European Commission the hurdles of a complex effect-based analysis - could be that of commitments by Google. Such alternative - which was about to be followed also in Europe - would have at least two virtues. First, it opens to a rapid solution, consistent with the potential harmful effects of Google's behaviours and with the speed of market dynamics. Second, it allows Google to be part of the process to come up with a viable solution, thus bringing information and data which would be otherwise precluded to antitrust authorities and regulators or, alternatively, very expensive to acquire.

\section{Questions and conclusions}

Looking at the Google case, it seems that the antitrust legal framework as it stands is unable to satisfactorily deal with search engines, where innovation, as the relevant driver, is responsible for creating and revolutionising the feature of the market and the business models of its market players. This proposition seems to be confirmed under three different arguments at least.

First, to correctly frame the Google case, it is not redundant to mention that what was questioned in the $\mathrm{SO}$ is how Google allocates its space on its general search results pages. The Commission, in fact, does not question Google algorithms, nor does it contest their use. Such distinction is not as sharp as it seems.

On the one hand, the Commission does not want to challenge the innovative service introduced by Google, nor does it intend to open a debate on whether, and to what extent, the algorithms invented by search engines to display and rank their results shall be disclosed and transparent.

On the other hand, however, the Commission risks being ambiguous when it points out that its concern is that "users do not necessarily see the most relevant results in response to queries to the detriment of consumers

\footnotetext{
${ }^{78}$ Valeria Falce, "Digital Disruption, Innovation and Competition Law. How the Google Shopping Case is Fitting the Framework", Italian Antitrust Review 3 (2015): 165.
} 
and rival comparison shopping services, as well as stifling innovation". From such argument, in fact, the Commission seems to infer that it is the algorithm in itself that raises a competition law issue, being responsible for selecting some results instead of others. And in any case, who decides, and on which bases, whether a result is the most satisfying from the consumer perspective?

Second, the Commission identifies as relevant the general search results market and alleges the existence of a dominant position held by Google. However, the boundaries of such market seem to be very mobile, at least because of the sources of access to information available on the Internet, both for consumers (interested in search results) and for merchants (interested in advertising products and services).

From a consumer standpoint, next to "traditional" search engines, whose number is constantly increasing (e.g. Bing, Yahoo, Quora, DuckDuckGo), it is now possible to search the internet through research "assistants" (e.g. Apple's Siri and Microsoft Cortana). Furthermore, as the market in which the search engines operate is fast growing, new operators and services can rapidly enter the market: this is the case of specialised search (e.g. Amazon, Idealo, Guides, Expedia or eBay), as well as of social networks, such as Facebook and Twitter, which in addition to their typical function are capable of offering their users useful information, tips and advices. Last but not least, the demand is also satisfied through trusted and popular digital news and information sites, or thanks to mobile devices and apps considered accurate and specific search tools.

From a merchant standpoint, there are some sources to be considered, such as, among the others, merchant platforms like Amazon, eBay, AliExpress, Etsy and Rakuten, online search advertising, advertising on social networks and online display advertising.

In such very smooth context, the application of the test of the hypothetical monopolist could determine a further enlargement of the boundaries of the relevant market. Importantly, if market shares and search options vary greatly and at a given speed, a question arises as to what extent the antitrust definition of the market, within an official action, is able to really capture the market dynamics and its evolution.

Third, the Commission does not question the business model underlying the search results markets (as two-sided platform ${ }^{79}$ ), where free goods/

\footnotetext{
${ }^{79}$ European Commission, "Notice on the definition of relevant market for the purposes of Community competition law", Official Journal C 372, (9.12.1997): 5-13.
} 
services are provided to consumers and commercial services are offered to merchants. The Commission argues that, given that business model, a par condicio treatment should be applied at least by Google.

Of course, such discriminatory policy shall be criticised only if Google holds a dominant position. This seems to be the case, according to the file sheets, the firm having more than $90 \%$ of the general search market in the EEA.

However, it remains to be ascertained whether, despite such evidence, a competitive pressure is experienced in search markets, where product designs change very rapidly, different sources of access to information are available on the Internet, market shares have proven to be volatile and life cycles are inherently brief, and both the market and competitors at large do not suffer from an economic damage.

What seems even less clear is the economic impact on innovation and consumer welfare, ${ }^{80}$ thus qualifying for an antitrust harm. ${ }^{81}$

In such perspective, following the trend towards a more economically oriented approach in assessing multilateral conducts from the time of the 1999 Vertical Agreement Regulation, and in line with the Court decision both in Cartes Bancaires and in the Post Danmark cases, it seems advisable to pursue a more compelling effect-based approach also in connection with unilateral conducts in general and with the Google Shopping case in particular.

An effect-based approach could, in fact, provide for an effective means for measuring Google design policy overall effects on competition, innovation and consumer welfare. Besides, it could provide for a legal and economic harbour, so as to avoid any possible interference between the enforcement of competition law and the inferences of regulatory policies.

Should the overall harm caused by the Google strategy to competition, innovation and consumer welfare remain vague or inconsistent, it seems undisputable that the principle of freedom to compete and win the selection "for" the market shall prevail, with the consequence that 1) no

\footnotetext{
${ }^{80}$ For useful insights, David A. Crane, "Search Neutrality and Referral Dominance", Journal of Competition Law \& Economics 8, 459-467; David A. Crane, "After Search Neutrality: Drawing a Line between Promotion and Demotion", I/S: Journal of Law and Policy for the Information Society 9 (3) (2014): 397-406.

${ }^{81}$ European Commission, "Guidance on its enforcement priorities in applying Article 82 of the EC Treaty to abusive exclusionary conduct by dominant undertakings". Official Journal C 45, 24.2.2009, 7-20; Damien Geradin, "Is the Guidance Paper on the Commission's Enforcement Priorities in Applying Article 102 TFEU to Abusive Exclusionary Conduct Useful?" (2010) (http:// ssrn.com/abstract=1569502).
} 
competitor shall be limited in its capability to design its products, meaning that also Google shall be free to provide for tailored results in order to catch both the consumers' and the advertisers' attention in the search markets; 2) no rival shall be limited in its ability to offer its advertising space on its platform at its own conditions.

Without such evidence, it seems that each rival shall contribute to the process of creative destruction, without any protection or subsidy.

\section{Bibliography}

Almunia, Joaquin. "Press conference, Statement on the Google investigation", Brussels, 5 February (2014), http://europa.eu/rapid/press-release_SPEECH-14-93_en.htm.

Bork, Robert H., and Gregory. G. Sidak. "What Does the Chicago School Teach about Internet Search and the Antitrust Treatment of Google", Journal of Competition Law and Economics (2012): 663-700

Bower, Joseph, and Clayton Christensen. "Disruptive Technologies: Catching the Wave", Harvard Business Review 73 (1995): 43-53.

Bracha, Orel, and Frank Pasquale. "Federal Search Commission? Access, Fairness, and Accountability in the Law of Search", Cornell Law Review 93 (2008): 1149-1209.

Bruzzone, Ginevra. "Le restrizioni per oggetto nella giurisprudenza della Corte di giustizia: alla ricerca di un approccio sistemico", Paper presented at the V Antitrust Symposium, Trento, April 17, 2015 (unpublished manuscript on file with the author).

Carrier, Michael A. "Google and Antitrust: Five Approaches to an Evolving Issue", Harvard Journal of Law \& Technology Occasional Paper Series (2013).

Crane, David A. "After Search Neutrality: Drawing a Line between Promotion and Demotion", Journal of Law and Policy for the Information Society 9, 3 (2014): 397-406.

Crane, David A. "Search Neutrality and Referral Dominance", Journal of Competition Law \& Economics 8 (2010): 459-467.

Comandini, Vicenzo Visco. "Google e i Mercati dei Servizi di Ricerca su Internet", Mercato Concorrenza Regole XV- 3 (2013): 541-570.

De Streel, Alexandre, and Pierre Larouche. "Disruptive Innovation and Competition Policy Enforcement", TILEC Discussion Paper, November (2015).

Edelman, Benjamin. "Does Google Leverage Market Power through Tying and Bundling?”, Journal of Competition Law \& Economics 11 (2015): 365-400.

European Commission. "Antitrust: Commission probes allegations of antitrust violations by Google", 30 November (2010), http://europa.eu/rapid/press-release IP-10-1624_en.htm?locale=en.

European Commission. Press release, "Antitrust: Commission sends Statement of Objections to Google on comparison shopping service; opens separate 
formal investigation on Android”, Brussels, 15 April 2015, http://europa.eu/rapid/ press-release_IP-15-4780_en.htm.

Falce, Valeria. "Digital Disruption, Innovation and Competition Law. How the Google Shopping Case is fitting the Framework", Italian Antitrust Review 3 (2015): 165-175.

Falce, Valeria, and Massimiliano Granieri. "La search neutrality tra regolazione e abuso di posizione dominante", Mercato, Concorrenza e Regole (2016): 289-312.

Falce, Valeria, and Massimiliano Granieri. "Searching a Rationale for Search Neutrality in the Age of Google", in Colangelo-Falce (eds), Concorrenza e comportamenti escludenti nei mercati dell'innovazione, Cap. IV, 2017.

Filistrucchi, Lapo, Damien Geradin, Erin van Damme, and Pauline Affeldt. "Market Definition in Two-Sided Markets: Theory and Practice", Journal of Competition Law \& Economics 10 (2014): 293-339.

Gal, Michal S., and Daniel L. Rubinfeld. "The Hidden Costs of Free Goods: Implications for Antitrust Enforcement", available on www.ssrn.com.

Geradin, Damien. “Is the Guidance Paper on the Commission's Enforcement Priorities in Applying Article 102 TFEU to Abusive Exclusionary Conduct Useful?” (2010) http://ssrn.com/abstract=1569502.

Goldman, Eric. "Revisiting Search Engine Bias", William and Mitchell Law Review 38 (2011): 96-102.

Grimmelmann, James. "Some Skepticism about Search Neutrality", The Next Digital Decade (2010): 435-455, available at http://james.grimmelmann.net/files/articles/ search-neutrality.pdf.

Grimmelmann, James. “The Structure of Search Engine Law”, Iowa Law Review 93 (2007): 1 .

Hazan, Joshua G. "Note, Stop Being Evil: A Proposal for Unbiased Google Search", Michigan Law Review 111 (2013): 789 -820.

Körber, Torsten. "Common errors regarding search engine regulation - and how to avoid them", European Competition Law Review 36, 6 (2015).

Lao, Marina. “Neutral' Search as a Basis for Antitrust Action?”, Harvard Journal of Law \& Technology Occasional Papers Series (2013): 1-12.

Niccolai, James. "Yahoo! Vows Death to the '10 Blue Links", PCWorld (May 19, 2009), http://www.pcworld.com/article/165214/yahoo_vows_death_to_blue_links.html.

Odlyzko, Andrew. "Network neutrality, search neutrality, and the never-ending conflict between efficiency and fairness in markets", www.ssrn.com.

OECD. "Hearing on disruptive innovation" DAF/COMP(2015).

OECD. "Report on data-driven innovation", 2015, available at http://www.oecd.org/sti/ data-driven-innovation-9789264229358-en.htm.

Osti, Cristoforo. "Ma a che serve l'antitrust?", Il Foro italiano V (2015): 121-141. 
Pasquale, Frank. "Internet Nondiscrimination Principles: Commercial Ethics for Carriers and Search Engines", The University of Chicago Legal Forum (2008): 1-20.

Pasquale, Frank. "Paradoxes of Digital Antitrust: Why the FTC Failed to Explain its Inaction of Search Bias", Harvard Journal of Law \& Technology Occasional Paper (2013).

Patterson, Mark R. "Google and Search-Engine Market Power", Harvard Journal of Law \& Technology (July 19, 2013).

Podszun, Rupprecht. "The More Technological Approach: Competition Law in the Digital Economy", in Competition on the Internet, edited by G. Surblyte, 101-108. Berlin: Heidelberg, 2015.

Renda, Andrea. "Searching for Harm or Harming Search? A Look at the European Commission's Antitrust Investigation against Google", CEPS Special Report 118 (September 2015).

Rifkin, Jeremy. “The zero marginal cost society”, New York (2014).

Salinger, Michael, and Robert Levinson. “The Role for Economic Analysis in the FTC's Google Investigation", unpublished manuscript (2013), available at http://www.law. northwestern.edu/ (last visit, July 7, 2017).

Shu, Tong. "Reflections on Baidu Monopoly Litigation: Comments on Renren v. Baidu", China Patents \& Trademarks 1 (2010): 66-71. 